\title{
Integrating Managerial Accounting and Accounting Information Systems
}

Alan S. Levitan, (levitan@louisville.edu), University of Louisville

Sidney J. Baxendale, (sjbaxe01@ulkyvm.louisville.edu), University of Louisville

\begin{abstract}
A problem in any curriculum is that students tend to regard courses as isolated modules. In fact, it is the integration of material from different courses, requiring higher level cognitive skills, which often leads to the solution of real issues. This paper describes a project in which students who were simultaneously enrolled in managerial accounting and accounting information systems built a system using concepts from both courses to accomplish systems and managerial objectives.
\end{abstract}

Introduction

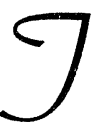

he Accounting Education Change Commission (1993, p. 436) has stated that, "(t)o effectively design curricula and develop courses the teacher must integrate courses with other related courses." Indeed, it is lamentable when students view an individual course as a module that is not integrated with other courses.

Writing specifically about reforming accounting education, Doyle Z. Williams (1993, p. 78) said, "In the traditional accounting curriculum, each course in tax, managerial accounting, financial accounting, systems and auditing is taught with little or no acknowledgment of the impact of the other topics. CPAs can attest to the irrationality of such an approach since business decisions cannot be made without considering all sides of the issues." Accordingly, we have developed a project that integrates manage-

Readers with comments or questions are encouraged to contact the authors via e-mail. rial accounting with accounting information systems (AIS) courses.

Accounting is an information system, and the AIS course is naturally related to all of the other accounting courses. A company's AIS must satisfy the users' needs for information related to financial, managerial, tax, and auditing requirements. Consequently, AIS can be better learned when applying the theoretical concepts to concrete examples from the other areas.

Similarly, managerial accounting data must be captured at its source, processed, managed, controlled, and turned into useful information. Students will be better prepared to practice managerial accounting if they understand where these data originate within the AIS, and if the students actually design an information system for managerial accounting through the entire cycle. 
The goal of this endeavor, then, is to synthesize material from different accounting subjects. Education theory defines the objective of synthesis as "a process of working with elements, parts, etc., and combining them in such a way as to constitute a pattern or structure not clearly there before. Generally this would involve a recombination of parts of previous experience with new material, reconstructed into a new and more or less well-integrated whole" (Bloom, et al., 1956, p. 162). In Bloom's model, synthesis is the second highest cognitive objective. (The highest is evaluation, followed by synthesis, analysis, application, comprehension, and finally knowledge.)

This article describes a venture to direct students who are simultaneously enrolled in the AIS course and the advanced managerial accounting course to take projects from the two independent courses and synthesize them. In doing so, the students create a new, well-integrated system. Our success in this shows that this integrated pedagogy is valuable because of the higher order skills the students achieved.

\section{The AIS Project}

One of the most important parts of the AIS course is a project where the class is divided into groups, with each group designing a cycle for the hypothetical company. For example, one group designs a general ledger cycle, one group designs an expenditure cycle, and one group designs an inventory/product conversion cycle. As each group prepares its flowcharts and layouts for files, screens, and reports, it must recognize that it may be collecting input that is to be used by another group.

All of the cycles are built with a relational data base management system (RDBMS). DBase III Plus had been traditionally used because of its minimal system requirements and its compatibility with other RDBMSs. Since the software can be run on hardware as primitive as PCs with dual 5.25-inch floppy drives and $256 \mathrm{~K}$
RAM, the project may be more easily run on students' home machines as the groups develop their systems. Microsoft Access is now used instead of dBase.

With an RDBMS, each group creates its own flat files, or tables; however, these files may be needed in forming relationships with other files, often in other cycles. For example, raw materials is related to purchases, which in turn is related to vendors and to cash payments. Work-in-process is related to jobs and factory operational data. Finally, finished goods is related to sales, which is then related to customers and to cash receipts.

Thus, the needs of the entire company must be considered at each developmental stage, and the subsystems, both within a system and across systems, must be compatible. As actual data are created, one system's output is another system's input. If the general accounting system needs the account code to contain a subfield for sales territory for subsequent responsibility reporting, the revenue system must collect and include it. This, then, becomes a good student integrative experience, as well as a realistic systems experience.

Figure 1 presents a flowchart of the students' activities. The first column of the flowchart represents the activities in the AIS class. The rest of the flowchart shows how these activities interface with the activities in the managerial class, which are described in the next section.

\section{The Managerial Project}

The managerial accounting course emphasizes activity-based costing (ABC) and activity-based management (ABM) concepts through the use of projects that contrast $A B C$ and $A B M$ with traditional managerial accounting.

The students convert a traditional master budget based on standard costs into an activ- 


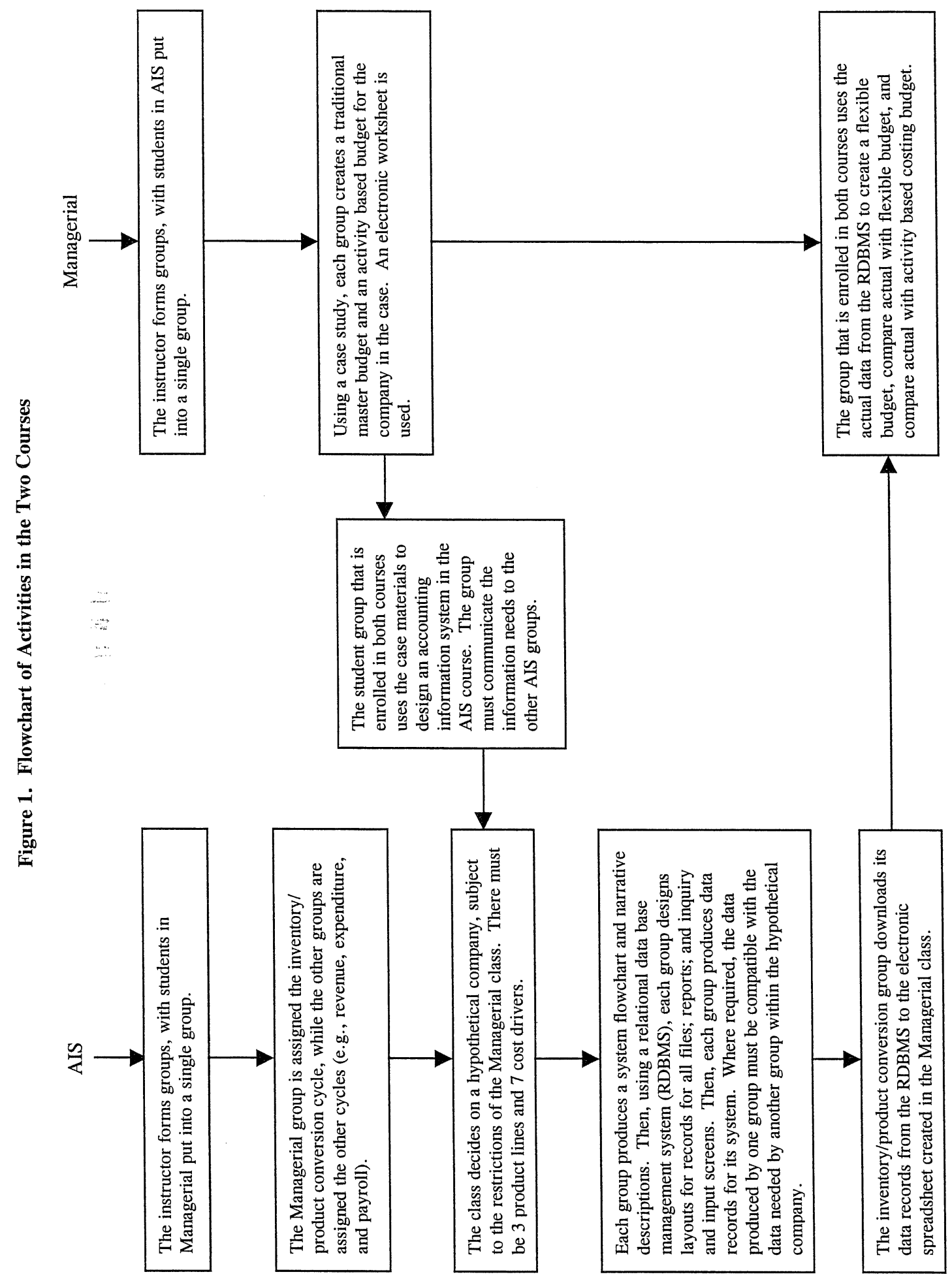


ity-based budget. The activity-based budget is established on the fragmentation of the overhead and shared costs into activities; the specification and use of budgeted cost driver information for each activity; and the specification and use of capacity estimates for the cost drivers of each activity.

Each of these budgets (master and activity-based budget) is placed in an electronic spreadsheet. The budgeted revenues and pre-tax income are identical for each budget. The master budget is organized by traditional account classification (product costs and period costs); however, the activity-based budget is organized by activity with the cost driver and capacity indicated for each activity.

When the students receive data from the AIS class project representing actual volume, costs, and revenues, they will be able to prepare a flexible budget. The flexible budget calculates the income statement based upon budgeted unit costs and prices at the actual sales volume level. They will furthermore be able to compute traditional cost variances by comparing actual costs with the flexible budget. These variances include the spending and efficiency variances for direct materials, direct labor, and variable overhead and the traditional fixed overhead budget variance and the fixed manufacturing overhead volume variance. Additionally, the students use the actual cost and revenue numbers and the budget to calculate the sales mix and yield variances.

The same actual data are used as a basis for comparison with the activity-based budget. This comparison focuses on budgeted idle capacity vs. actual idle capacity for each activity. In order to make this comparison, the students must read and understand a research paper (Baxendale and Levitan, 1995) that focuses on the control potential that exists within an activitybased accounting system. The performance evaluation examines the actual unused capacity vs. the budgeted unused capacity for each of the activities. The students use a technique described by Shank and Churchill (1977), in which a single variable (e.g., machine hours, maintenance hours) is changed in turn to actual while the rest are held to budgeted amounts. This technique allows the students to discern how much of the variance in unused capacity was caused by a change in capacity, a change in the budgeted relationship between activities, or a change in production volume.

\section{The Integrated Project}

It must be emphasized to students that all aspects of business are interrelated and complementary. One way to accomplish this is to show that different accounting courses are indeed interrelated.

We achieved this by selecting students who were enrolled in both the advanced managerial course and the AIS course in the same semester. These students were chosen to be a group in both classes. In the AIS course, they were given the responsibility of designing the inventory/product conversion cycle for the hypothetical company. Like the other cycles, it was to be built with a relational data base management system (RDBMS).

The assignment in the managerial course was to develop a spreadsheet model to compute the traditional variances (actual vs. flexible budget). In addition, the model was expanded to compute activity unused capacity variances revealed by an $\mathrm{ABC}$ system. The $\mathrm{ABC}$ system revealed the unused capacities as a result of having specified the budgeted capacity, in terms of the activity driver, for each activity. The actual unused capacities were based on the actual capacities, relationships between activities, and production that were downloaded to the spreadsheet model from the database.

The challenge for the students working on the joint project was to design a manufacturing cycle that would be compatible with the other 
cycles from the other student groups in the AIS class (e.g., revenue, expenditure, and payroll). This is because all subsystems must interface through the RDBMS in the common company and produce and maintain data representing actual costs to permit the computation of all the variances in the managerial class. Hence, having designed inputs and files to gather and store actual data in the AIS class, they were instructed to translate/download electronically the appropriate information from the database into the electronic spreadsheet developed for the project in the managerial class.

All the students in the AIS class had learned, in a previous exercise, techniques for translating data from an RDBMS into an electronic spreadsheet. For example, dBase has a "copy to file type wks" command to export all or selected records and fields of a data base to a worksheet-formatted file with rows and columns. Then Lotus, for example, has a "file-combinecopy" command to incorporate all or part of one spreadsheet file into another one at a specified location. Microsoft Office, and similar current software suites, allows the translation of databases into spreadsheets seamlessly through a few mouse clicks.

The students who were enrolled in both the managerial and the AIS courses had to download the following actual data prepared from the accounting system developed in the AIS course: (1) Unit sales for each product; (2) Unit sales price for each product; (3) Expenses for each activity specified in the activity-based budget and each account in the traditional budget; (4) Usage of the cost driver for each of the activities; (5) Relationship between the cost drivers for activities that are related. (For example, the actual number of maintenance hours per machine hour); and (6) Actual capacity for each activity.

\section{The Mechanics of Timing}

The timing of the assignment of the projects in the two courses must be coordinated. Those students who are enrolled in both courses are briefed early in the semester about their additional responsibilities, their need to have their group's project satisfy the requirements of both courses. Then, about halfway into the semester, these students begin to realize the significance of the need for compatibility.

The projects start in earnest in both courses midway in the semester. During the first half of the semester in the managerial course, the students are learning about $\mathrm{ABC}$ concepts. The second half of the course is devoted to the development of the activity based model of the team's selected company.

In the AIS course, the first half of the semester deals with basic systems concepts, hardware and software, files and databases, and documentation tools. Then, as the teams start developing their systems during the second half, they are concurrently learning about systems design and analysis, controls, and the accounting cycles.

During the final weeks of the semester, the students download the actual activity based information from the database created in the AIS course into the $\mathrm{ABC}$ model that they built in the managerial course. This is, indeed, the proof that fields created in the AIS project can be mapped into activities for the $\mathrm{ABC}$ project, in addition to their need to be compatible with the fields from the other AIS groups.

\section{Summary}

This integration of projects in the two related courses enabled the students to gain an understanding of how diverse accounting information needs can and should be met. The students in the classes who were not in the joint group were kept informed of the progress as well. Thus everyone learned, through actual or observed experience, the importance of carefully planning for all information requirements during 
the design of a system. They were pleased with the approach and saw the value of the integration.

The project demonstrated that accounting courses may be broken into subject areas for teaching purposes, but are actually interdependent and part of the same system. It also tapped the highest levels of cognitive learning objectives, requiring the creation of a system and critical inquiry involving analysis, synthesis, and evaluation. The success of this pedagogical approach warrants further study into ways to make accounting classroom subjects as interrelated as they actually are in application. [a]

\section{References}

1. Accounting Education Change Commission, "Evaluating and Rewarding Effective Teaching: Issue Statement No. 5," Issues in Accounting Education, Vol. 8, No. 1, pp. 436-439, 1993.

2. Baxendale, Sidney J. and Alan S. Levitan, "Performance Evaluation Using the Unused Capacity Costs Revealed by an Activity Based Costing System," Proceedings of the Annual Meeting of the Southeastern Region of the American Accounting Association, 1995.

3. Bloom, B. S. et al. Ed. Taxonomy of Educational Objectives, David McKay Company, New York, 1956.

4. Shank, J. K. and N.C. Churchill, "Variance Analysis: A Management Oriented Approach," The Accounting Review, Vol. 52, No. 4, pp. 950-957, 1977.

5. Williams, Doyle Z., "Reforming Accounting Education," Journal of Accountancy, Vol. 176, No. 2, pp. 76-82, 1993. 